\title{
ALGUNAS PLANTAS EN BILLETES, BOLETOS DE CAFÉ Y CAFETALES DE COSTA RICA $(1836-2004)^{1}$
}

\author{
José A. VArgas-Zamora ${ }^{2,4}$ y Jorge GÓmeZ-LaUrito ${ }^{2,3}$ \\ ${ }^{2}$ Escuela de Biología, Universidad de Costa Rica. 2060 San José, Costa Rica. \\ ${ }^{3}$ Investigador Asociado, Dept. Botany. Field Museum of Natural History, Chicago, Il. USA. \\ ${ }^{4}$ Autor para correspondencia: javargas@cariari.ucr.ac.cr • (506) 207-3201
}

\begin{abstract}
The bank notes and coffe tokens of Costa Rica include illustrations of several species of plants. The leaf of the Acanthus sp. plant is used as an ornament in paper money from the mid XIX century to the end of the XX century. The most widely known botanical illustration of Costa Rica is the orchid, Guarianthe skinneri, the national flower, featured in the 5 colones bank notes issued from 1968 to 1992. The most common illustration in coins since 1935 is the coffee (Coffea arabica) branch (bandola) with fruits. Coffee tokens, used in Costa Rica since the mid of the XIX century, include a variety of plant forms representing the coffee tree. Coffee tokens also include illustrations of other plants, like the myrtle (Myrtus communis). The coffee industry in Costa Rica had its origins in 1840 with the first coffee exports, and soon coffee became the main crop of the country. In this work we cite some species used in coffee plantations as live fences and shade, and also some common weeds. We also mention several plant fibers used in the elaboration of the canastos, the baskets used to collect the ripe coffee fruits.
\end{abstract}

Resumen. Los billetes bancarios y los boletos de café de Costa Rica incluyen ilustraciones de varias plantas. La hoja del acanto (Acanthus sp.) es utilizada como ornamentación en muchos billetes desde mediados del siglo XIX hasta finales del siglo XX. La ilustración botánica más conocida es la orquídea Guarianthe skinneri, flor nacional de Costa Rica, incluida en el anverso de los billetes de 5 colones emitidos de 1968 a 1992. El grabado más común desde 1935 en las monedas es la rama (bandola) del café (Coffea arabica) con frutos. Los boletos de café, en uso en Costa Rica desde la mitad del siglo XIX, incluyen varias formas de representar al arbusto del cafeto. También se utilizaron boletos con ilustraciones de varias especies de otras plantas, como el mirto (Myrtus communis). La industria cafetalera en Costa Rica tuvo sus inicios en 1840 con las primeras exportaciones y se convirtió en el principal cultivo del país. En este trabajo citamos los nombres de algunas plantas asociadas a la actividad cafetalera, incluyendo algunas malezas, árboles utilizados para definir los límites de los cafetales y para sombra, así como algunas fibras vegetales utilizadas en la elaboración de los canastos para recoger el fruto maduro.

Palabras clave / Key words: Numismatics, coins, paper money, coffee tokens, coffee plantations, Acanthus, Guarianthe skinneri, Coffea arabica, Ceiba pentandra, Laurus sp., Myrtus sp., Olea sp., Costa Rica.

En nuestro artículo anterior (Vargas Zamora \& Gómez Laurito 2004) hicimos un análisis de las ilustraciones de plantas incluidas en las monedas de Costa Rica durante los siglos XIX y XX. Ahí enfatizamos que los nombres comunes o vernáculos, como palmera, ceiba, tabaco, café, encina, mirto y laurel, son los mencionados en documentos relacionados con la acuñación de monedas. Esto hace difícil asociar, con base en la ilustración en la moneda, la planta más

\footnotetext{
1 Conferencia impartida en el Auditorio 290, Escuela de Biología, UCR, Ciudad Universitaria, 27 de abril del 2005.
}

semejante a la identificada con un nombre cientifico. Por ejemplo, para las monedas con la encina, hay en Costa Rica doce posibles especies del género Quercus (Burger 1977), cuyos árboles pudieron servir de modelo, y varias más en Europa, si el modelo fue una encina europea. En el caso del tabaco y del café las ilustraciones coinciden con las únicas especies cultivadas en Costa Rica, Nicotiana tabacum (Solanaceae) y Coffea arabica (Rubiaceae), respectivamente. Para el mirto y el laurel existen en el país dos especies asociadas a esos nombres comunes: Murraya paniculata (Rutaceae) y Cordia alliodora (Boraginaceae). No 
obstante que los grabadores incluyeron ilustraciones muy variadas del mirto y del laurel, éstas pueden asociarse a las especies europeas cuyos nombres científicos son Myrtus communis (Myrtaceae) y Laurus nobilis (Lauraceae). En este escrito aportamos nuestro criterio sobre algunas ilustraciones botánicas, que fueron grabadas en billetes bancarios y boletos de café, desde mediados del siglo XIX, así como en algunas monedas del siglo XX. También hemos considerado oportuno incluir información sobre los cafetales y su entorno.

Las monedas de Costa Rica tienen grabadas varias ilustraciones de plantas. El uso de motivos botánicos se inicia con una palmera en las primeras monedas de 1825 y continúa con representaciones de la ceiba, el tabaco, el café, la encina, un alga marina, la flor y el árbol nacionales (Guarianthe skinneri, Orchidaceae, y Enterolobium cyclocarpum, Fabaceae), así como el mirto y el laurel (Vargas Zamora \& Gómez Laurito 2004). Esto contrasta con la poca variedad encontrada en los billetes emitidos por los bancos del país desde 1858 hasta el presente. En los libros de Chacón Hidalgo \& Alvarado Venegas (2001) y Carranza Astúa (2001) notamos que en los billetes de Costa Rica las ilustraciones principales son: leones, águilas, edificios gubernamentales, escudos nacionales, iglesias, monumentos, buques, la carreta típica, trenes, volcanes, una catarata, retratos de próceres, gobernantes, banqueros, lecheros y cafetaleros, figuras mitológicas y alegorías, además de la Reina Victoria, la Mona Lisa, Cristóbal Colón y algunos ángeles pintados por Rafael Sanzio (1483-1520). A partir de 1952 y hasta 1970 se incluyó, en los billetes del Banco Central de Costa Rica (BCCR) de 20 colones, series A y B, así como desde 1997 en los de la serie A de 2000 colones, el retrato del Dr. Clodomiro Picado Twight, el biólogo más destacado de Costa Rica en la primera mitad del siglo XX, con cuya tesis doctoral (Picado 1913) sobre las bromelias epífitas y otros trabajos se adelantó a su tiempo.

En este escrito varias de las figuras tienen reproducciones de monedas, boletos de café y billetes. En algunos casos hemos ampliado, o reducido, las dimensiones originales, las cuales se indican en el pie de la mayoría de las figuras.

\section{LOS VALES DE TABACO}

El Diccionario define el término vale como: nota o apuntación firmada y a veces sellada, que se da al que ha de entregar una cosa, para que después acredite la entrega y cobre el importe (UTEHA 1953). Por tanto, podemos llamar vales a los recientemente descubiertos (Green 2003, 2004 a, b) y considerarlos como los primeros documentos, similares a billetes, relacionados con el comercio de una planta, el tabaco (Nicotiana tabacum), en Costa Rica. Estos vales se originaron en agosto de 1836, cuando los diputados decretaron, en vez del impuesto directo sugerido por don Braulio Carrillo, la venta forzosa del tabaco que hay en las tercenas (= almacenes regionales) mediante la adjudicación a los habitantes con capacidad para ello, en todos los pueblos; en proporción con su número, para hacer frente a diversos gastos ordinarios y de otra indole; principalmente en el ramo de la seguridad, con motivo de la emergencia causada por la incursión de Quijano. Seguidamente el 8 de setiembre se reglamenta la cantidad de tabaco que debe asignarse a cada lugar (Villalobos Rodríguez et al. 2000: 196). Los cinco vales de tabaco hasta ahora encontrados están fechados el 18 de septiembre de 1836, como el ilustrado en la Fig. 1. No había bancos

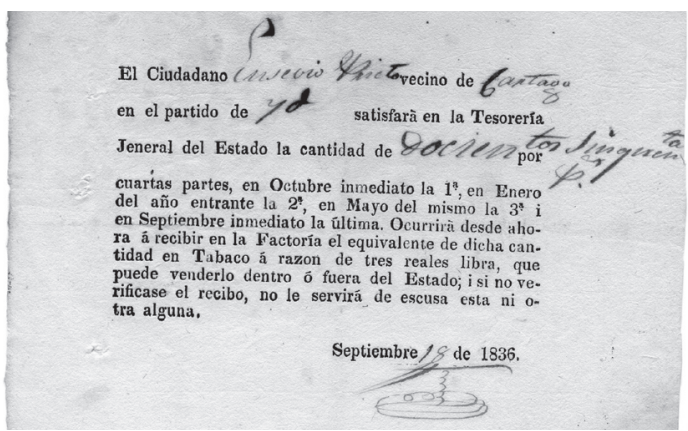

Fig. 1. Documento comercial denominado vale de tabaco, emitido por la Tesorería General del Estado de Costa Rica, el 18 de septiembre de 1836 al ciudadano Eusevio Prieto, vecino de Cartago, por un valor de 250 pesos en tabaco, a tres reales la libra, para vender dentro o fuera del territorio nacional y reintegrar el total del dinero en cuatro entregas. Dimensiones $(15.8 \mathrm{~cm}$ x $10.9 \mathrm{~cm})$, papel blanco con marca de agua, impreso por un solo lado. Firma y espacios llenados con plumilla a tinta. Colección privada. 
en la Costa Rica de 1836. El primero fue el Banco Nacional Costarricense (1858-1859) y los primeros ejemplares de papel moneda hasta ahora conocidos son los vales de 5 y 10 pesos, emitidos en 1839, para facilitar el pago de los salarios de los empleados públicos a los que les servían, además, para pagar una cuarta parte de los impuestos de las importaciones, comprar terrenos baldíos o realizar otras transacciones (Carranza Astúa 2001, Chacón Hidalgo \& Alvarado Venegas 2001).

\section{EL ACANTO Y EL LAUREL}

En el estudio de la gráfica en el papel moneda de Costa Rica realizado por Chacón Hidalgo \& Alvarado Venegas (2001) se indica que, si bien los grabados de los billetes por lo general no respondían a imágenes concretas de nuestro contexto, pues eran compradas a los fabricantes, la selección de estas obedecía al hecho de que transmitian de manera genérica diversas concepciones relativas a las bases y aspiraciones políticas, económicas y culturales de la sociedad costarricense, ... las casas de fabricación de papel moneda inglesas y estadounidenses contaban con un repertorio básico de imágenes simbólicas representativas, asumidas en occidente como universales.

En este contexto, la ilustración botánica utilizada con más frecuencia en billetes, sellos de correo y otros documentos de Costa Rica fue la hoja del acanto europeo (Fig. 2A, B, C). Esta es una planta ornamental, herbácea, anual, con hojas opuestas grandes rizadas, cuyos grabados están basados en dos especies del género Acanthus (Acanthaceae): A. mollis, cultivada con frecuencia, que posee hojas lisas no punzantes y A. spinosus, la especie silvestre, con hojas rizadas punzantes. Las hojas son el modelo base del capitel corintio ideado por el arquitecto griego Calímaco, quien vivió 400 años antes de Cristo. Los artistas griegos no se inspiraron más que en el acanto espinoso por ser el que crece en Grecia, pero los latinos emplearon también el cultivado. Sin embargo, los romanos en el período imperial lo transformaron, de modo que es posible observar plantas con tallos y extremos de las hojas más redondeados y fue usado con una mayor amplitud y suavidad de formas que las empleadas por los griegos clásicos. El acanto cultivado (A. mollis) más flexible, fino y elegante, base de la ornamentación romana, con el tiempo fue modificado mediante la adición de detalles tomados de otras plantas, como el perejil (Petroselinum crispum, Apiaceae). Los romanos también introdujeron modificaciones basadas en las hojas del laurel (Laurus nobilis). La planta de $A$. mollis alcanza un metro de altura y hojas de hasta $50 \mathrm{~cm}$, pinnatipartidas, con bordes sinuosos, flores blanquecinas o rojizas y su fruto es una cápsula. A. spinosus tiene las hojas más partidas y con cortos dientes espinosos en los lóbulos casi triangulares (Espasa 1924, Bartolini 1949). En la Fig. 2 (A, B, C) podemos apreciar algunas de las variaciones de la forma básica de la hoja de acanto grabada en el primer sello postal del país (1863), así como en dos billetes
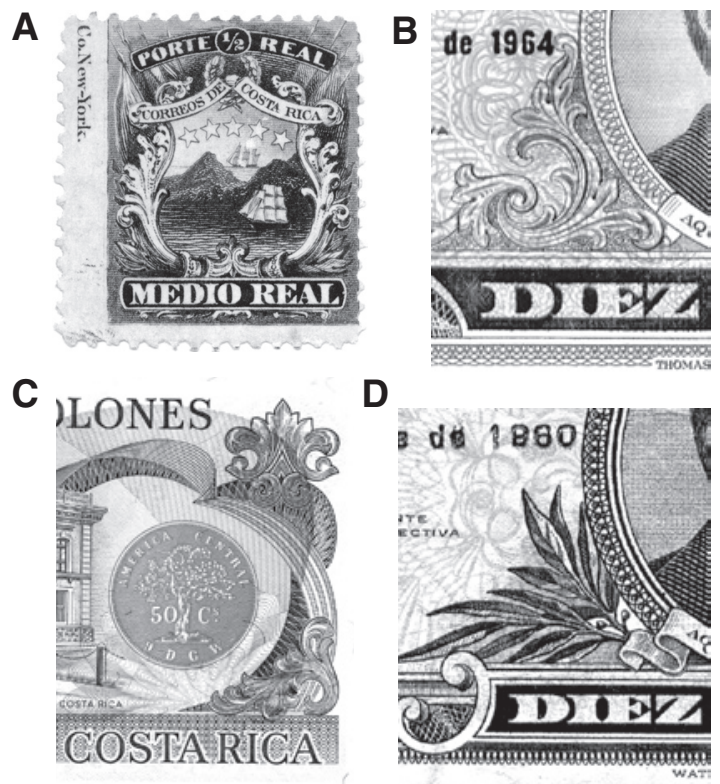

Fig. 2. Ornamentaciones basadas en hojas de la planta de acanto (Acanthus sp.) y del laurel (L. nobilis): A. Sello de correos de Costa Rica. Impreso en tinta azul por Bradbury and Wilkinson, New York, $26 \mathrm{~mm} \mathrm{x}$ $28 \mathrm{~mm}$. Las hojas del acanto forman los costados del escudo nacional. B. Sección central del billete de 10 colones, 1964, Banco Central de Costa Rica (BCCR). C. Extremo derecho del billete de 50 colones, 1991, BCCR (Nótese la imagen de la moneda con el árbol de Quercus sp., o encina). B y C impresos por Thomas de la Rue \& Co. D. Sección central del billete de 10 colones, 1960, BCCR, con la rama de laurel y dos frutillos pedunculados en la base. Colección privada. 
de Costa Rica. Los últimos billetes con una ilustración basada en el acanto son los de 500 colones, Series B, C, y D, emitidos de 1979 a 1994, cuyos reversos incluyen la fachada del Teatro Nacional de San José. En este edificio, inaugurado en 1897, se utilizaron las hojas del acanto (Ulloa Zamora 1970) como ornamento de las lámparas, palcos y otras estructuras, tal como se ilustra en el folleto de Obregón Quesada (1996). Para la decoración del Teatro no se invitó a artistas (pintores) costarricenses (Ferrero 1981). En algunos billetes de 10 colones, grabados por Waterlow \& Sons Ltd., se incluyeron a ambos lados de la base de la imagen del poeta Aquileo Echeverría, ramas del laurel europeo (L. nobilis, Fig. 2 D), especie utilizada desde la antigüedad para honrar a personajes destacados.

Entre otras ilustraciones sobre temas botánicos, como motivos principales en los billetes, podemos mencionar la canasta con piñas (Ananas comosus, Bromeliaceae) y una planta de banano (Musa acuminata, Musaceae) en el billete de 5 colones de 1914, así como la de una plantación de café (Fig. 3A), posiblemente de algún país del Caribe o de Brasil, en el billete de 10 colones, ambos de la Serie A del Banco Internacional de Costa Rica (BICR). En 1919 se grabó la imagen de una plantación cubana (?) de caña de azúcar (Saccharum officinarum, Poaceae) en el billete de 20 colones de la Serie C del BICR. También relacionado con el tema del café, los billetes de 5 colones de 1931 a 1936 (BICR, Serie D) muestran cogedoras de café y al fondo plantas de café y banano (Fig. 6D). La ceiba (Ceiba pentandra, Bombacaceae) aparece en el reverso del billete de 50 colones, serie C, 1972-1977 del Banco Central de Costa Rica (BCCR). La ceiba ilustrada (Fig. 3B) fue plantada en 1963 en el jardín de la Casa Amarilla (San José) y a la fecha es un gigante con un tronco de más de un metro de diámetro.

\section{LA GUARIA MORADA}

La ilustración botánica más conocida está en los billetes de 5 colones, Serie D del BCCR, emitidos desde 1968 hasta 1992, que incluye dos flores de la orquídea Guarianthe skinneri (Orchidaceae), la flor nacional de Costa Rica (Fig. 4A). El dibujo de las dos guarias moradas en el billete fue hecho por el
A

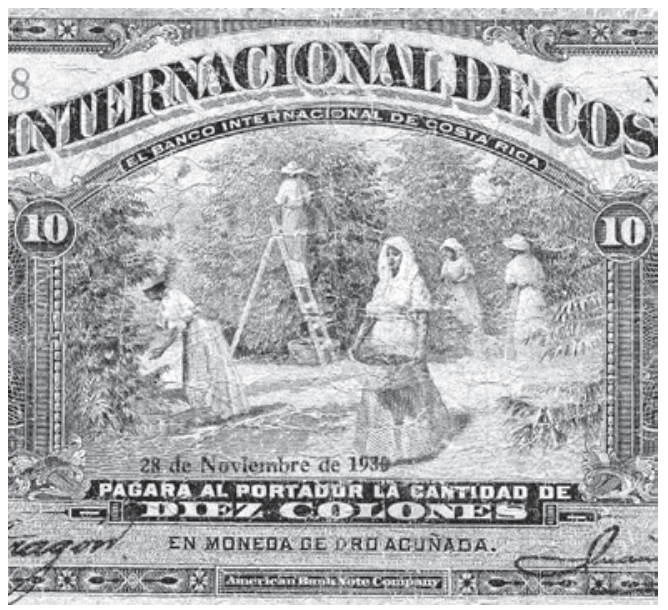

B

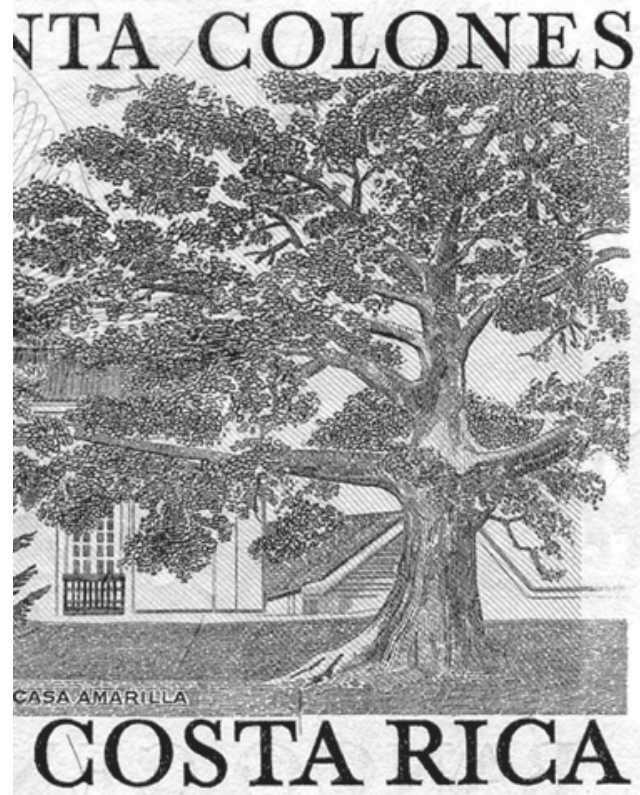

Fig. 3. Secciones central (A) y lateral (B) de: A. Billete de diez colones, Serie C, del Banco Internacional de Costa Rica (BICR), emitidos entre 1919 y 1932, mostrando la cosecha del café en una plantación caribeña (Jamaica ?) o brasileña. Nótese la gran altura de los arbustos y la recolección del grano utilizando una escalera. Ni el cogedor en la escalera ni las cuatro damas llevan el canasto, más ancho que alto, atado a la cintura. B. Extremo derecho del billete de 50 colones, Serie C, del BCCR, 1974, con el grabado de la ceiba $(C$. pentandra). Colección privada.

Dr. Rafael Lucas Rodríguez Caballero (1915-1981), estudioso de esta familia de plantas en Costa Rica. Guarianthe skinneri florece en el Valle Central en los 
A

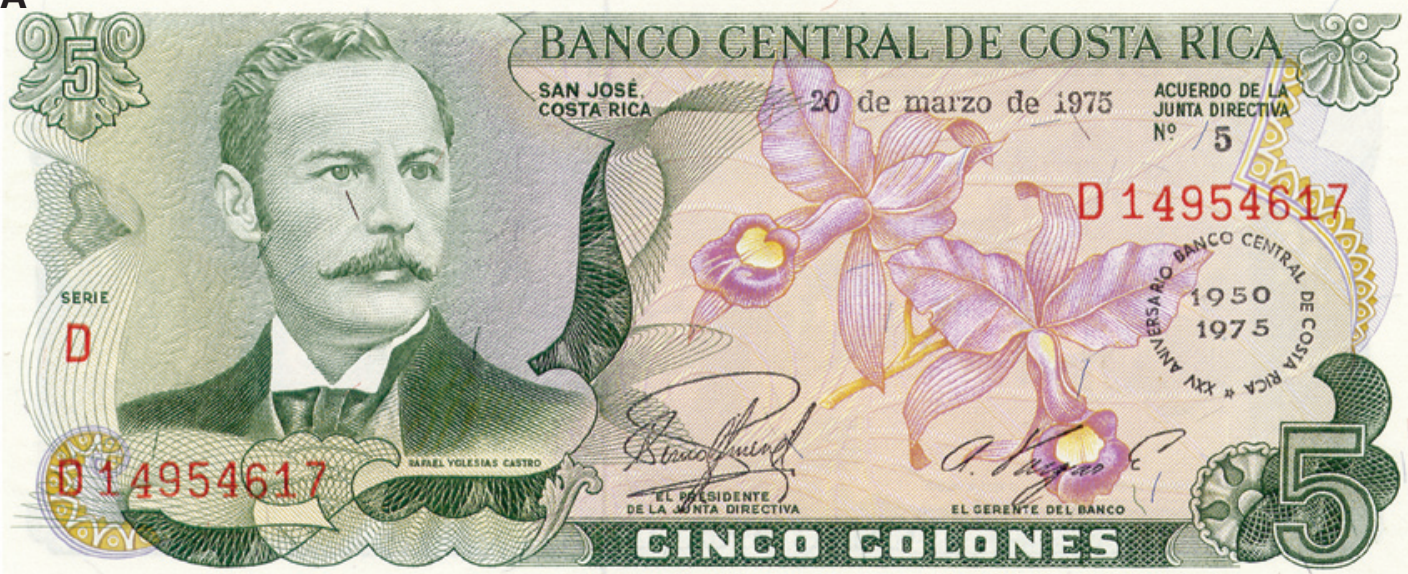

B

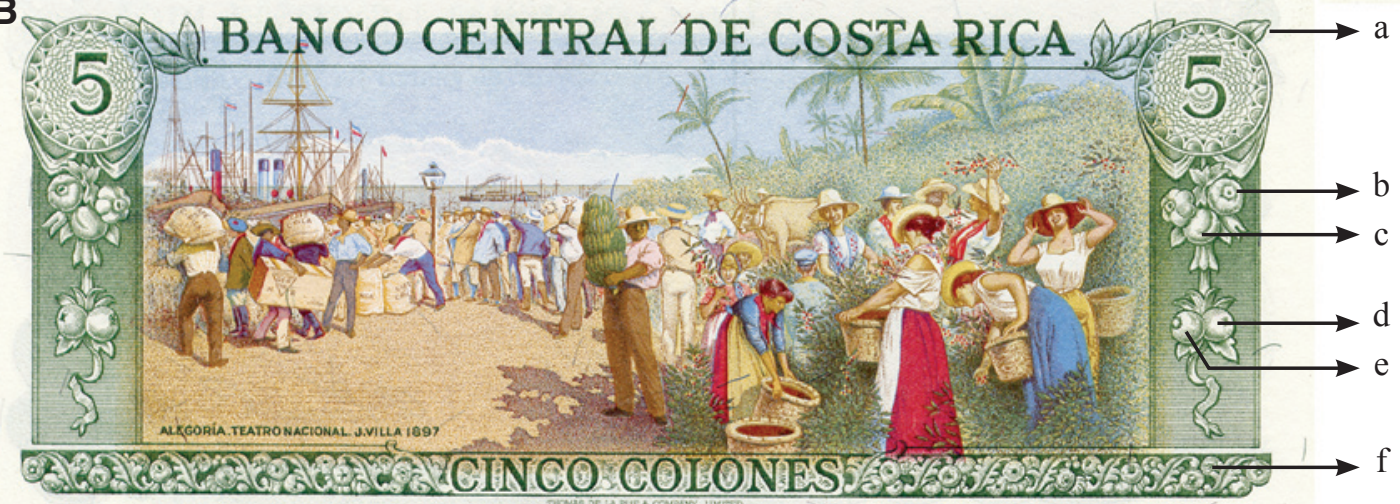

Fig. 4. Anverso (A) y reverso (B) del billete de cinco colones, Serie D, del Banco Central de Costa Rica (BCCR). Fue emitido entre 1968 y 1992 y el ilustrado incluye el sello conmemorativo del XXV aniversario de BCCR en 1975. Casa impresora: Thomas de la Rue \& Co. Ltd., $15.7 \mathrm{~cm} \mathrm{x} 6.7 \mathrm{~cm}$. En el anverso se incluyen como motivos principales la efigie de don Rafael Yglesias Castro, Presidente de Costa Rica (1894-1902), y dos flores de la guaria morada (Guarianthe skinneri, Orchidaceae), flor nacional de Costa Rica por decreto del 15 de junio de 1939. Nótese, en el extremo superior izquierdo, las hojas de acanto rodeando al 5. En el reverso se ilustra la alegoría de la caficultura del maestro italiano Aleardo Villa (la inicial J en el billete es un error), pintada en Milán, Italia, en 1897. La pintura está colocada en el cielo de la gran escalinata del Teatro Nacional de Costa Rica, San José. Las plantas indicadas por las flechas son: a) Hojas de laurel (?), L. nobilis; b) Higo sicomoro (F. sicomorus); c) Ciruela (P. domestica); d) Higo común (F. carica); e) Amapola (P. rhoeas $)$; f) Manzana amarga (C. colocynthis). Estas plantas no son parte de la pintura original. Colección privada.

meses de febrero y marzo (estación seca). Esta orquídea pertenecía al género Cattleya, pero fue asignada recientemente al nuevo género Guarianthe con base en un análisis de ADN del grupo Cattleya (Dressler \& Higgins 2003). A la izquierda de las flores se ilustra el retrato de don Rafael Yglesias Castro, Presidente de Costa Rica de 1894 a 1902. Durante su gobierno se abandona la unidad monetaria llamada peso de 100 centavos. En 1896 dispuso la acuñación de una moneda con $778 \mathrm{mg}$ de oro de 900 milésimas a la que se llamó colón, dividido en 100 céntimos. En el año siguiente fueron acuñadas monedas de oro de 2, 5, 10 y 20 colones, con la efigie del Almirante Cristóbal Colón, pero la de un colón se acuñó hasta en 1935 (Gurdián Montealegre 1996). En el reverso del billete (Fig. 4B) se reproduce la pintura del maestro italiano Aleardo Villa (1865-1906), quien la realizó en Milán, Italia, con base en información enviada desde Costa Rica (Obregón Quesada 1996, Bariatti 2000). No hemos logrado comprobar si alguna de las dos figuras 
con capa de artista, que aparecen junto al farol, es el autorretrato del pintor. El farol no es un detalle trivial: San José fue la segunda ciudad del mundo en inaugurar el alumbrado eléctrico ( 9 de agosto de 1884) y esto debió sorprender al pintor. Sin embargo, el farol ilustrado corresponde al primer alumbrado de petróleo (1851), cuyas lámparas de cuádruple reverbero fueron construidas en Francia y los pedestales en Inglaterra (Zeledón Cartín 2004). La pintura representa una gradiente desde las plantaciones de café en el Valle Central, sombreadas por una musácea en el extremo derecho hasta, a la izquierda, la exportación del grano seco en sacos de gangoche, a bordo de buques de vapor por el puerto de Limón, según se lee en la caja que carga un estibador. Las hojas de la planta de banano concuerdan con las de las especies del género Musa. Sin embargo, si el artista quiso representar palmeras tropicales con base en la información que le fue enviada, las dos ilustradas son más afines a la especie de palma datilera Phoenix dactylifera (Arecaceae), por el tipo ondulado del tronco y su copa, que al cocotero (Cocos nucifera, Arecaceae). En el medio destaca un hombre de tez oscura, bien vestido y calzado, sosteniendo un racimo de bananos (Musa acuminata) del modo en que lo haría alguien, a quien se le solicitara levantarlo para exhibirlo, esto es: tomando el extremo más grueso del raquis con la mano izquierda y levantando el extremo colgante, donde estuvo la chira (espata que envuelve la inflorescencia), con la mano derecha, quedando así los bananos con sus extremos libres hacia arriba. Destacan, además, entre las cogedoras de café y otros personajes, los sombreros de ala ancha fabricados usualmente de pita (Carludovica palmata, Cyclanthaceae). Como marco a la alegoría encontramos algunas especies de plantas seleccionadas, tal vez por la casa impresora: en la parte superior dos ramas de laurel (?) y a ambos lados frutos del higo sicomoro (Ficus sycomorus, Moraceae) que simbolizan la durabilidad. La madera de esa especie fue usada en el antiguo Egipto para construir sarcófagos. Colgando en los costados del billete aparecen dos tipos de frutos: uno de ciruela (Prunus domestica, Rosaceae) y otro de higo común (Ficus carica, Moraceae), que simbolizan la abundancia. Luego un fruto de amapola roja (Papaver rhoeas, Papaveraceae) que representa la belleza efímera. En la base del billete, y fácil de confundir con hojas de Acanthus, un cintillo de hojas y frutos de manzana amarga (Citrullus colocynthis, Cucurbitaceae), que simboliza la simetría.

Entre los billetes recientes, emitidos por el Banco Central de Costa Rica, están los de cinco mil colones, series A,B,C, en circulación a partir de 1991 y diseñados por Leonidas Correa en 1987 (Carranza-Astúa 2001). El reverso incluye, además de una esfera precolombina de piedra y un ídolo (Fig. 5 d, k), el tucán (Fig. 5 f), Rhamphastos swainsoni (ver Stiles \& Skutch 1989) y un jaguar (Panthera onca, Fig. 5 i), conocido por nuestros campesinos como el tigre o el manchado (Valerio 1944). En contraste con las plantas utilizadas como ornamentación en el billete de 5 colones (Fig. 4), que son especies conocidas mundialmente y asociadas a algún rito o tradición, las plantas ilustradas en el billete de 5000 representan especies restringidas a bosques de Costa Rica, lo que hace aún más difícil el asignar nombres científicos con base en las ilustraciones. Además, atributos morfológicos útiles en la identificación, como flores y frutos no están incluidos o la escala no permitió dar suficiente detalle, con excepción de la inflorescencia de la heliconia (Fig. 5 j), que hace posible el identificarla como Heliconia pogonantha (Heliconiaceae), según se describe en Berry \& Kress (1991). Para las otras plantas hemos optado por sugerir (Fig. 5) el nombre genérico más afín al de la planta grabada en el billete. El lector interesado puede consultar a Hammel et al. (2003) para información sobre las bromelias (Bromeliaceae) y las palmas del piso del bosque (Arecaceae).

\section{EL CAFÉ Y LOS CAFETALES}

Las ilustraciones basadas en el arbusto del café, sus ramas y sus frutos, son importantes en la numismática costarricense desde 1847. En la actualidad, la actividad cafetalera está cambiando rápidamente, e involucra la desaparición paulatina de plantaciones y del uso de los boletos de café. Por tal motivo hemos considerado oportuno incluir la siguiente información para el lector, nacional o extranjero, no familiarizado con este cultivo en Costa Rica.

El café (Coffea arabica) es un arbusto de uno a varios metros de altura, con frecuencia multicaule, ramas opuestas, largas, flexibles y delgadas. Posee hojas opuestas, brillantes, verde oscuro, ovaladas, 


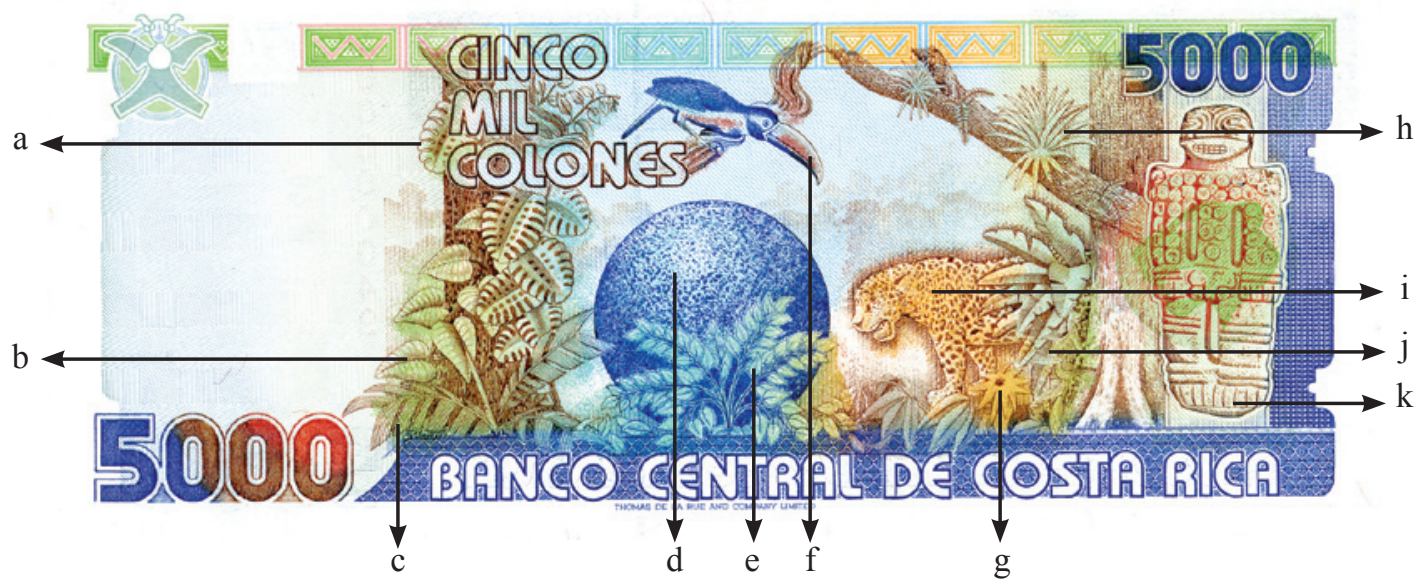

Fig. 5. Reverso del billete de cinco mil colones, serie A, 1991, del Banco Central de Costa Rica: a) Monstera sp., Araceae; b) Philodendron sp., Araceae; c) Calyptrogyne sp., Arecaceae; d) esfera de piedra; e) género no identificable; f) tucán, R. swainsoni, posado sobre el bejuco Bauhinia sp.; g) Bromeliaceae; h) Werauhia sp., Bromeliaceae; i) jaguar, Panthera onca; j) Heliconia pogonantha, Heliconiaceae; k) ídolo de piedra.

acuminadas, de 10 a $15 \mathrm{~cm}$ de largo, con pecíolo corto, bordes lisos ondulados y nervaduras conspicuas. El café es originario de las tierras altas de Etiopía y Sudán. Se le introduce en América Central en El Salvador (1740), Guatemala (1750) y en Costa Rica entre 1796 y 1808 (ICAFE 1989, Meléndez 2000). La primera exportación de café fue de dos quintales $(1$ quintal $=100$ libras $=46 \mathrm{~kg}$ ) en el año 1820 por el puerto de Puntarenas. En 1832 los envíos se realizan hacia Chile y a partir de 1843 hacia Inglaterra en forma directa (Meléndez 2000). A principios del siglo XIX, el cultivo del café comenzó a competir con el del tabaco, que era el producto más importante, hasta que en la década de 1840 el café constituía el $80 \%$ del valor de las exportaciones de Costa Rica. En 1840 se exportaron 8341 quintales y para 1848 fue de 96544 quintales (Molina 1987). El café no forma parte o tiene una presencia esporádica en la mesa del costarricense hasta avanzada la década de 1850 (Vega Jiménez 2004).

El tamaño de las primeras plantaciones de mayor extensión en las vecindades de la ciudad de San José era variable y como ejemplo citamos la de don Juan Rafael Mora con 50 manzanas y 84000 arbustos. Sin embargo, en 1848 don Vicente Aguilar (Fig. 11 A) vende una finca de café cuya área era de 357 manzanas
(Molina 1987). En la región de Turrialba, en el año 1837, don Narciso Esquivel, agricultor de Cartago, declaró tener, además de cacao sembrado, plátano y café, por lo cual solicitó el título de propiedad y se le dieron 11 caballerías en forma gratuita por las mejoras introducidas (Solano Pérez 1995). Entre 1838 y 1850 el $50 \%$ de los cafetales tenían menos de 5 manzanas de extensión (Molina 1987), y ya en 1935 el $75 \%$ de las plantaciones eran de un área menor a 2 manzanas ( 1 vara española $=0.836 \mathrm{~m}, 100$ varas $=83.6 \mathrm{~m}$, una manzana $=6989 \mathrm{~m}^{2}$, una caballería $=64.7$ manzanas). Este alto porcentaje de pequeñas fincas permaneció así durante la mayor parte del siglo XX. Sin embargo, la etapa de procesamiento del café en fruta se mantuvo controlada por los grandes productores. El lector interesado en la relaciones entre habilitados (productores generalmente) y los habilitadores (grandes productores, beneficiadores, exportadores), así como sobre los conflictos sociales derivados de ella, puede consultar a Acuña Ortega (1986), Molina (1987) y Gudmundson (1990).

Los límites o linderos de cafetales grandes o minúsculos eran marcados por las filas (= cercas) de árboles, como los de madero negro (Gliricidia sepium, Fabaceae), entre los cuales a veces crecía un jocote (Spondias purpurea, Anacardiaceae) o el 
poró tico (Erythrina costaricensis, Fabaceae) con su flor roja semejante a un pequeño cuchillo, o el güitite (Acnistus arborescens, Solanaceae), o el itabo (Yucca guatemalensis, Agavaceae) cuya inflorescencia comestible es parte de la cocina campesina costarricense. En regiones de clima mas cálido, eran frecuentes las cercas del árbol llamado indio chingo (Bursera simarouba, Burseraceae). Para dar sombra al cafeto se sembraban plantas de varias especies del género Inga (Fabaceae) como la guaba caite (I. paterno) y el largo cuajiniquil (I. oerstediana), que además de la sombra contribuían con sus hojas ricas en nitrógeno a la fertilización del suelo (Zamora \& Pennington 2001). El sombreado de los cafetales, con matas de plátano (Musa paradisiaca, Musaceae) y con esos árboles dejó paso a la siembra de otras especies como el poró extranjero (Erythrina poeppigiana, Fabaceae). El lector puede consultar las obras de Soto (1985), León (1987) y Fournier \& García (1998) sobre los nombres de las especies del género Musa, los cultivos tropicales y los nombres vernaculares y científicos de los árboles de Costa Rica, respectivamente.

A mediados del siglo XX, en la actual Área Metropolitana, hoy casi cubierta de asfalto y urbanizaciones que ocupan los sitios de antiguos cafetales, la cosecha $(=\operatorname{cogida})$ de café empezaba por ahí de fines de noviembre, más o menos coincidente con el cierre del curso lectivo para que los niños pudieran participar y acumular algún dinero para la navidad. Para ir a coger café es y era necesario poseer un canasto.

Es el canasto un recipiente cilíndrico elaborado a mano tejiendo fibras vegetales (Fig. 6A, B) de varias especies (Alfaro 2003). Entre las fibras más utilizadas están las cucharillas Amphilobium paniculatum y Cydista diversifolia (Bignoniaceae) y otras bignoniáceas como el bejuco hueco (Styzophyllum inaequilaterum), el ajillo amarillo (S. riparium), el parruá (Clytostoma binatum), el güititón (Paragonia pyramidata) y el granadillo (Mussatia hyacinthina), mencionados por Palma \& Chaves (2000). También se emplean los bejucos jurisos, Serjania acuta, $S$. rufisepala (Sapindaceae), el bejuco de canasto, Smilax subpubescens (Smilacaceae), y el ojo de buey, Mucuna urens (Fabaceae), que son plantas trepadoras y de ellas se utilizan los tallos. La capacidad del canasto era cercana a la unidad de medida o caiuela $(=20 \mathrm{~L})$, o un poco más grande. El canasto se

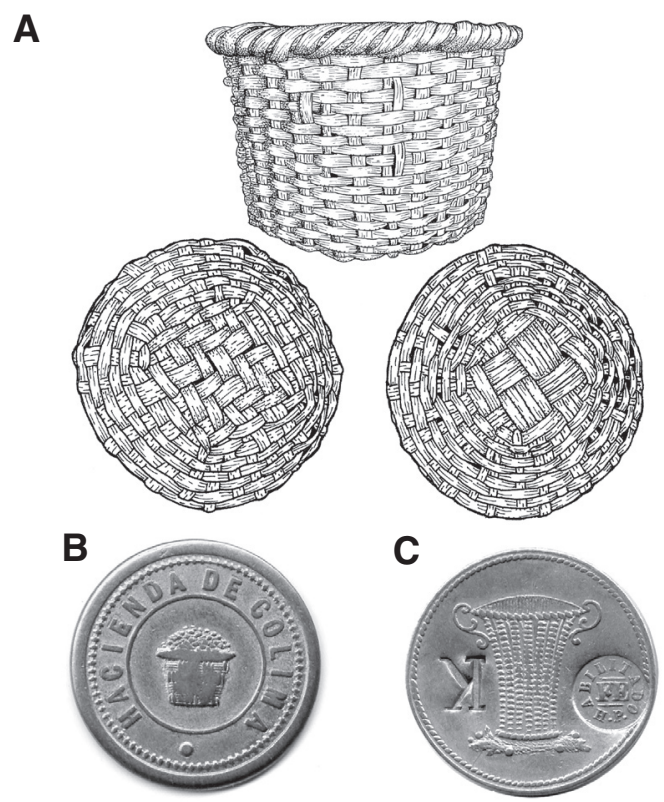

D

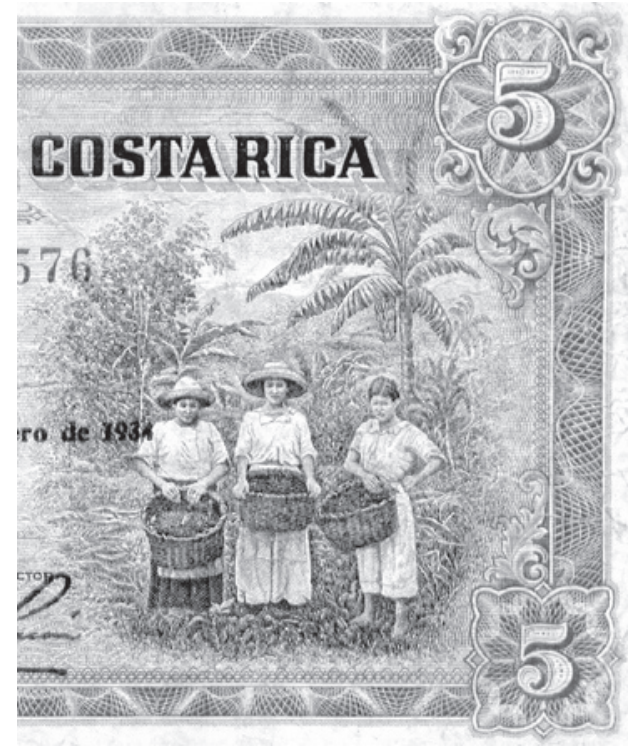

Fig. 6. A. Vista lateral de un canasto costarricense (diámetro $36 \mathrm{~cm}$, altura $28 \mathrm{~cm}$, peso $1.2 \mathrm{~kg}$, capacidad 28 litros, 8 litros más que una medida o cajuela) para la recolección del fruto del café y fondos de éste y otro canasto mostrando dos formas de entrecruzar las fibras vegetales utilizadas en su elaboración. B. Anverso de un boleto, con un canasto lleno de frutos del café. C. Reverso de otro boleto, ilustrando un canasto alto semejante a los utilizados en la vendimia europea. D. Extremo derecho del billete de cinco colones, Serie D, del BICR, emitidos entre 1931 y 1936, mostrando tres cogedoras en un cafetal de Costa Rica. Nótese el uso de la hoja de acanto (Acanthus sp.) modificada, en la ornamentación que rodea el 5. Colección privada. 
sujeta a la cintura con una faja (Alfaro 2003) hecha con un trozo de gangoche arrollado y a cuyos extremos se ata un mecate, ambos hechos a veces con la fibra de la cabuya (Furcraea cabuya, Agavaceae). La faja se ajusta bajo el borde del canasto y su longitud se modifica retorciendo el mecate con el trozo de una rama.

La cosecha del café se hacía, y algunos todavía la hacen, en tres etapas: la granea, la (s) cogida (s) y la repela. En la granea se cosechan los pocos granos que han madurado antes que la mayoría y para evitar su caída de la planta. El pago por cajuela durante la granea era, en algunas micro-plantaciones cuyos dueños sabían de la dureza del trabajo, a veces más alto que durante la cogida principal, pues se necesita realizar un mayor esfuerzo para recoger los granos maduros de entre los verdes, siendo menor el número de cajuelas por cogedor al final de la jornada diaria. La cogida principal se hacía unas semanas después y podía repetirse según avanzaba la maduración del grano. También unas semanas después, por ahí de fines de diciembre o mediados de enero se hacía la repela, donde tanto los granos maduros como los verdes eran recogidos. A veces se escogía el café para separar unos granos de otros, o se dejaba pal gasto (= para el consumo familiar), o se hacían ambas cosas. En esta etapa final el pago por cajuela era a veces más alto para compensar por el tiempo adicional invertido. La producción total del cafetal se medía y aún se mide en fanegas (1 fanega $=400$ litros o, de acuerdo con la jerga propia de la industria, una fanega $=$ dos dobles hectolitros). En la cogida en las pequeñas plantaciones participaba un grupo cercano a la docena de personas de la vecindad, generalmente ya conocidas del dueño y que eran casi siempre las mismas año tras año. Muchas veces el propio dueño del pequeño cafetal se integraba al grupo como cogedor. El precio por cajuela y la duración de la jornada diaria (se coge hasta las tres de la tarde) quedaban fijos desde el primer día de trabajo y los cogedores eran constantes en su labor hasta el último día de cosecha, pues se consideraba mal visto el abandonar lo empezado. Cada cogedor llevaba (= cosechaba) una o dos calles ( $=$ filas de arbustos) y al finalizarlas se hacía la junta, esto es, se recogía los granos que debido a la falta de pericia del cogedor no habían caído dentro del canasto. Luego se volvía al corte (límite entre las calles cosechadas y las sin cosechar) para empezar con una o dos nuevas calles. La pausa para el almuerzo por ahí de las nueve de la mañana era la ocasión propicia para intercambiar los chismes del barrio, evaluar el resultado de las jornadas pasadas y especular sobre las futuras.

El ovario de la flor del café da una drupa, llamada cereza, oval, roja (o amarilla en una variedad) cuando madura, hasta de $15 \mathrm{~mm}$ de ancho por 18 $\mathrm{mm}$ de largo, cubierta por un exocarpo coloreado, un mesocarpo carnoso blanco-amarillento y dos semillas unidas por sus caras planas (Figs. 7A, B). Cuando uno de los óvulos aborta, el otro se desarrolla dando una semilla ovoidea conocida como caracolillo (Coste 1968). Este nombre podría provenir de la similitud de las semillas con los caracoles (Fig. 7C) de la familia Cypraeidae, especialmente Cypraea arabicula, que en otros tiempos era muy abundante en las playas del Golfo de Nicoya (Keen 1971) y era conocido para los que, a mediados del siglo XIX y principios del XX, iban a dejar café en carretas al puerto de Puntarenas. Caracolillo era también el seudónimo que utilizó Manuel González Zeledón (Magón) en su cuento El grano de Oro (1934) en el que relata el progreso, desde peón hasta macroproductor-beneficiador, de un campesino costarricense a fines del siglo XIX (González Zeledón 1947). Los Cuentos de Magón son una valiosa fuente de información numismática (Vargas-Zamora 2005).

El café cosechado en el cafetal cada día era depositado en sacos de gangoche (Furcraea cabuya) con capacidad para unas tres cajuelas, o en sacos más grandes, que en este caso se llamaban sacas. Al final de la jornada diaria, se llamaba a medir el café, el cual se entregaba limpio de palillo (fragmentos de ramas), hojas y café verde. Entonces el boleto equivalente a la cantidad medida (cuartillo, media, o una medida) se depositaba en el canasto como signo visible del intercambio y el sábado el dueño del pequeño cafetal se los cambiaba a los cogedores por el equivalente en dinero, que ese día o el anterior se le había adelantado en el beneficio en el cual el dueño del cafetal estaba inscrito o habilitado. El café es llevado al patio de beneficio para quitarle la cáscara y secar la semilla al sol, tal como se ilustra en la Fig. 7D. Luego se le empaca en 

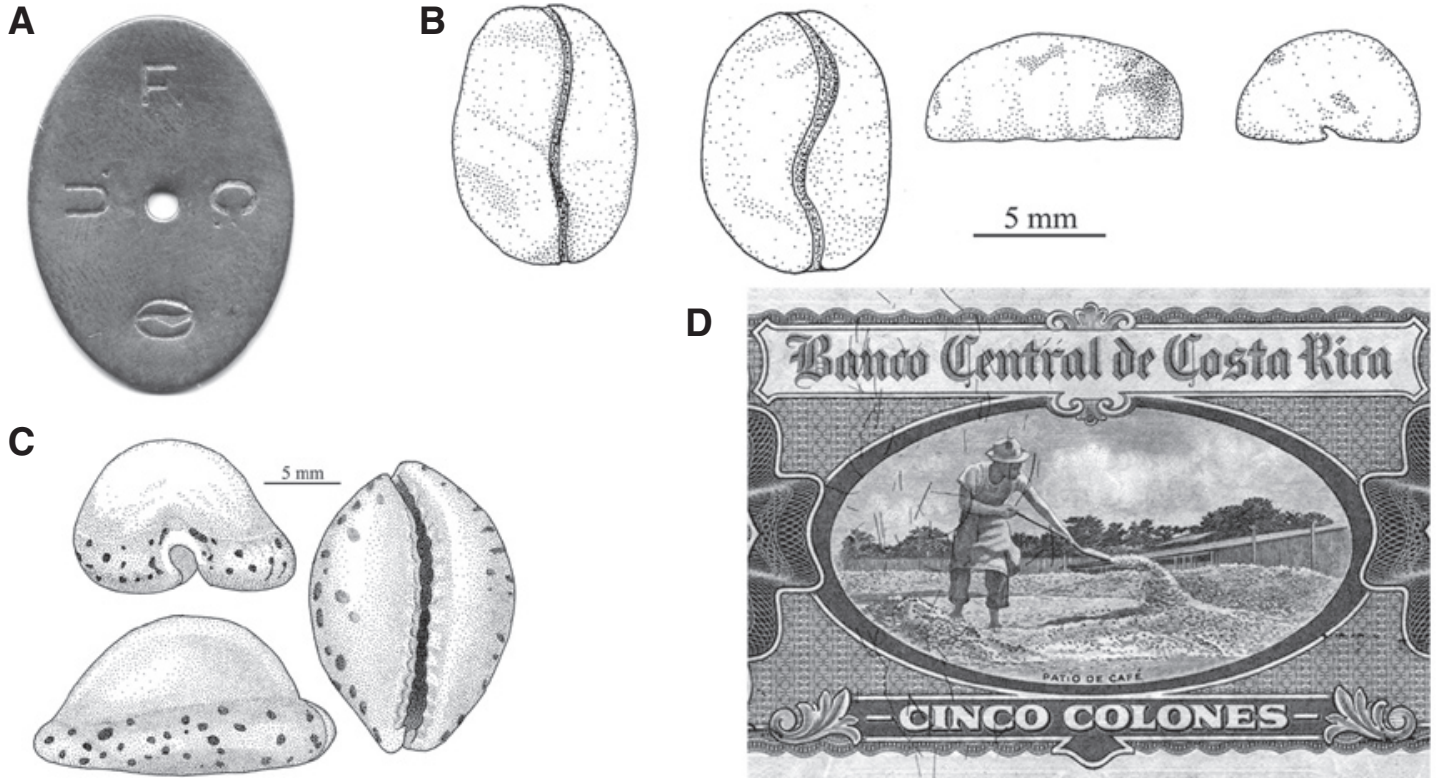

Fig. 7. A. Anverso de un boleto de la U.F.C (United Fruit Company) con grabado de semilla de café en bajorrelieve o incuso, $26 \mathrm{~mm}$. B. Semillas del café, constituidas en su mayor parte por endosperma coriáceo, verde o amarillento. C. Caracol (Mollusca, Gastropoda) marino de la especie Cypraea arabicula (Cypraeidae) del Golfo de Nicoya, cuya forma semejante a la semilla del café pudo dar origen al nombre café caracolito o caracolillo. D. Sección central del reverso del billete de cinco colones, serie B (1958 - 1962) del Banco Central de Costa Rica, con la ilustración de un palero removiendo semillas (granos) de café para su secado al sol en un patio de beneficio. Nótense las hojas de acanto en los extremos de -cinco colones-. Colección privada.

sacos de gangoche para su exportación (Fig. 4B).

Varias veces al año y según la necesidad, en los cafetales había que hacer la palea; es decir, la eliminación de las malezas mediante el uso de una pala. El oficio de palero era muy común en Costa Rica antes de la llegada de los herbicidas. Eran emblemas del oficio: la pala ancha limpia y afilada, el triángulo metálico que servía para raspar la tierra que se adhería a la pala, la lima para afilarla, el machete en su cubierta de cuero con el nombre grabado, el delantal de mezclilla azul hasta un poco más abajo de las rodillas (Fig. 7D) y el sombrero de lona. Se acostumbraba llevar un calabazo (fruto seco y ahuecado de Lagenaria siceraria, Cucurbitaceae) como recipiente para el agua que aplacaba la sed. El palero iniciaba su labor al amanecer y concluía, agotado y doblado, al mediodía. Entre las malezas más comunes para ser paleadas estaban la mielcilla (Jaegeria hirta, Asteraceae), las escobillas (Sida acuta y S. rhombifolia, Malvaceae), el coyolillo (Cyperus rotundus, Cyperaceae), el muriseco (Bidens pilo$s a$, Asteraceae) y las pudreorejas (Ipomoea spp.,
Convulvulaceae). La pala producía un ruido típico al cortar esas plantas, el cual ha descrito (Chavarría 2003) el poeta naturalista Lisímaco Chavarría (18781913), así:

Zas...zas...Resuena el tajo entre el cafeto bajo el sol que los páramos rescalda y dobla pudreorejas de esmeralda que simulan encajes en el seto.

El fresco manantial discurre inquieto, de la colina en la vistosa falda, y finge el cafetal una guirnalda, -joyel de Ceres de rubís repleto.

Zas...zas...zas...zas. Trabajan los paleros y sudan bajo el sol, en sus labores, mientras cantan yigüirros y jilgueros...

Para otras labores en los cafetales, como la poda, la deshija y la resiembra, el lector puede consultar el manual del ICAFE (1989) y el artículo de SolanoPérez (1995). 


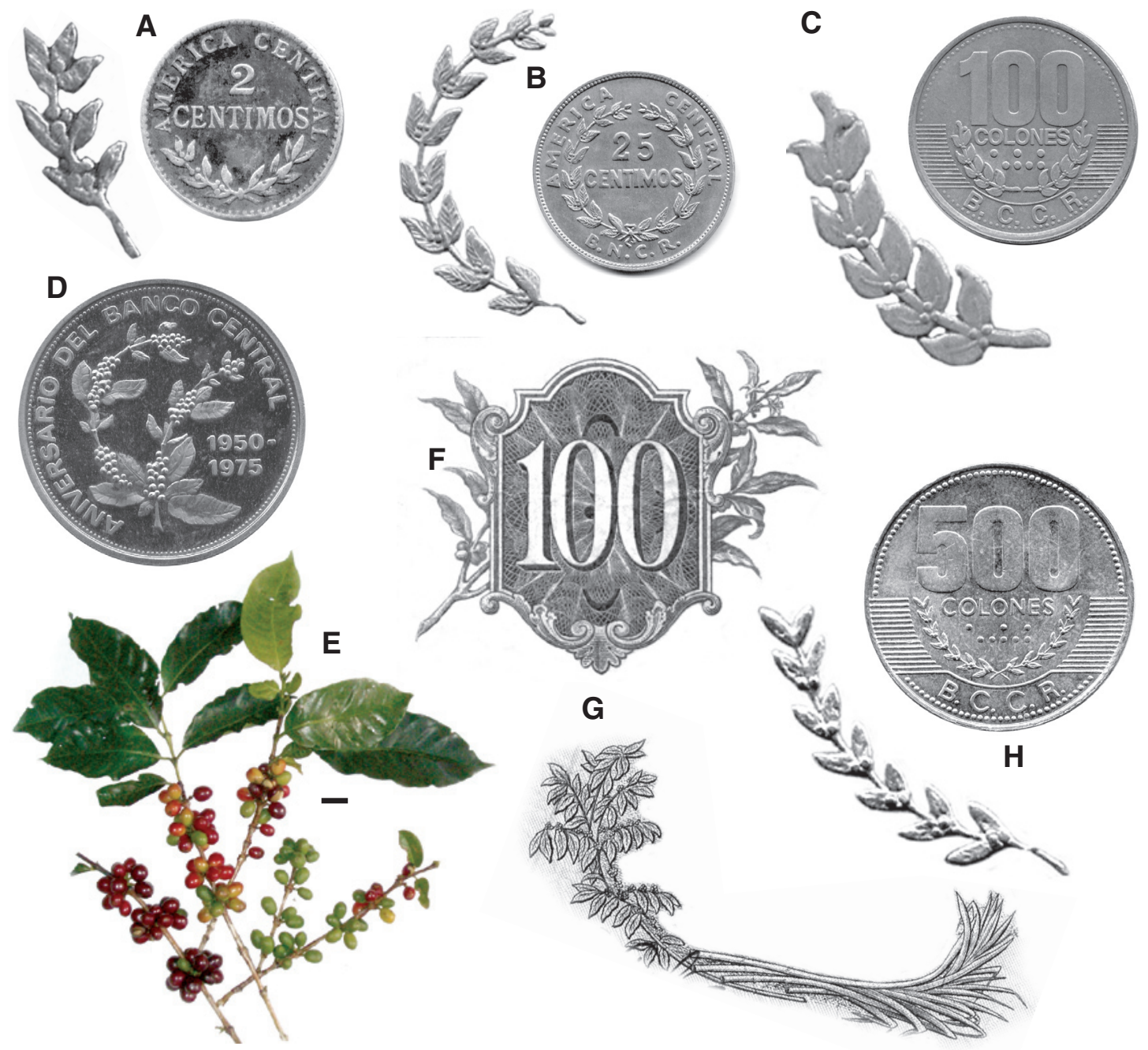

Fig. 8. La rama del cafeto (bandola) en monedas y billetes: A. Moneda de 2 céntimos, 1903, $15 \mathrm{~mm}$. La rama a la derecha es de mirto. B. Moneda de 25 céntimos, 1937, Banco Nacional de Costa Rica (BNCR), 23 mm. C. Moneda de 100 colones, Banco Central de Costa Rica (BCCR), 1995, 29.5 mm. D. Moneda conmemorativa del BCCR, Cinco colones, 1975,30 mm. E. Cuatro bandolas de café con frutos en diferentes etapas de maduración: verde, pintón (verde amarillento) y maduro (rojo), cafetal en Santo Domingo de Heredia en noviembre del 2004. Escala $30 \mathrm{~mm}$. F. Extremo izquierdo del reverso del billete de 100 colones, serie D, 1942, del BNCR. Nótese bajo el 100 la ornamentación basada en la hoja del acanto. G. Sección central del anverso del billete de 100 colones, serie D, 1972, del BCCR, con bandolas de café y cañas de azúcar. H. Reverso de la moneda de 500 colones, BCCR, 2003, 33 mm. Colección privada.

\section{LA BANDOLA DEL CAFÉ}

\section{EN LA NUMISMÁTICA COSTARRICENSE}

Después del acanto, la ilustración botánica más utilizada en las monedas y algunos billetes de Costa Rica es la rama (bandola) de café. Se le incluye por primera vez en las monedas de dos céntimos de 1903 (Fig. 8A) y luego, a partir de 1935 en forma continua, en la mayoría de las monedas del país, hasta la fecha, si bien su diseño ha sido modificado con el transcurso del tiempo. En la Fig. 8B, C, H se ilustran las monedas de 25 céntimos (1937), 100 colones (1995) y de 500 colones (2003) con las bandolas de café, además de la moneda conmemorativa de 5 colones de 1975 (Fig. 8D). En la Fig. 8F se incluye el extremo izquierdo del reverso del billete de 
100 colones, serie D, 1937-1942, del Banco Nacional de Costa Rica, con una bandola de café detrás de un escudo que contiene el número $100 \mathrm{y}$ cuyos bordes tienen ornamentaciones basadas en la hoja del acanto. La rama con bandolas de café, así como la caña de azúcar (Saccharum officinarum, Poaceae), aparecen en el centro del anverso del billete de 100 colones, serie D, 1969-1977, del BCCR (Fig. 8G). Para el lector no familiarizado con las bandolas de café, hemos incluido en la Fig. 8E varias bandolas con hojas y frutos en diferentes etapas de maduración.

\section{EL CAFÉ Y LAS MARIQUITAS}

En el artículo anterior (Vargas Zamora \& Gómez Laurito 2004) mencionamos que la primera moneda conmemorativa de Costa Rica (un real de 1847, Fig. 9A, B), así como las de un real de 1849 y 1850 , tienen en su anverso grabado un arbusto de café (Fig. 9B) y se les conoce como mariquitas (Gurdián Montealegre
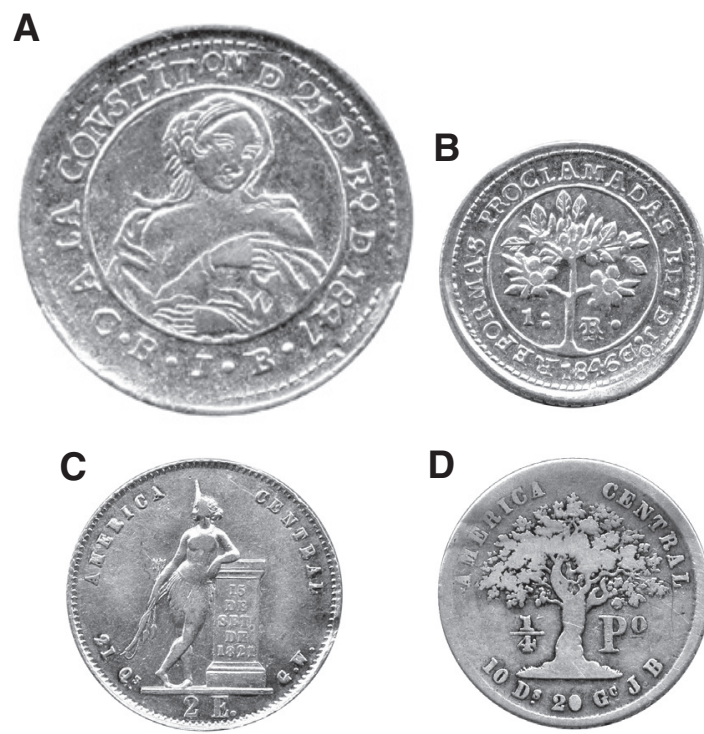

Fig. 9. Anverso (A) y reverso (B) de la primera moneda conmemorativa emitida en Costa Rica ( 1 real, plata, 1847), Casa de Moneda, San José. $20 \mathrm{~mm}$. Leyendas: A la Constitución del 21 de enero de 1847 (A); Reformas Proclamadas el 7-VI-1846 (B). C. Reverso de la moneda de dos escudos (2E), oro, Casa de Moneda de San José, 1855, $23 \mathrm{~mm}$, conocida como cuarta de india. D. Reverso de $1 / 4$ de peso, 1850, $23 \mathrm{~mm}$. Casa de Moneda de San José. El árbol es semejante a las encinas (Quercus spp.).
1996). Las monedas, contemporáneas de las mariquitas, llamadas de la india parada y de arbolito (Fig. 9C, D), fueron diseñadas para facilitar su aceptación en el mercado internacional, especialmente en el creciente comercio cafetalero con la Gran Bretaña (Chacón Hidalgo 2003, Vargas Zamora \& Gómez Laurito 2004) y bien podríamos llamar a este trío de monedas, las embajadoras. Se nos ha consultado acerca del origen del sobrenombre mariquitas, por lo que a continuación ofrecemos nuestra hipótesis: según el decreto de 1847 la moneda de un real contendrá por el reverso el rostro de una joven india (Gurdián Montealegre 1996, Fig. 9A). Al igual que en el caso de las monedas de la india parada y de la encina, la figura está posiblemente basada en modelos europeos, en este caso muy semejante a los incluidos en pinturas italianas del siglo XVI, como la Madona de Foligno de Rafael Sanzio (1515, Pinacoteca Vaticana), con la que comparte la cabeza inclinada mirando a la derecha y un tocado de estilo similar, o al retrato, según se ilustra en Cruells (2000), de Margarita Luti, La Fornarina (1519, Galería Nacional, Roma), con el que la imagen en la moneda comparte las siguientes características: 1. La figura vertical se extiende desde la cabeza hasta los brazos cruzados al frente, con el brazo izquierdo bajo el derecho. 2. El tocado del cabello muestra una tela, con bandas, arrollada alrededor de la cabeza y terminado en una cola. 3. El estilo de peinado dividido al centro. 4. La forma de sostener la tela del velo, entre los dedos índice y cordial de la mano derecha. 5. Los hombros descubiertos. 6. La ausencia de aretes y collares. Figuras como la arquera y los árboles de encina, así como tal vez las madonas de Rafael, eran conocidas para los europeos de la época, como Johan Barth, quien fue el ensayador de esas monedas (J.B. en Fig. 9 A, D) y para los intelectuales nacionales como el Dr. José M. Castro Madriz, quien el 10 de febrero de 1847 firmó el decreto para emitir la primera moneda conmemorativa de Costa Rica (Fig. 9 A, B) y el 29 de setiembre de 1848 el decreto de emisión de las monedas de la india parada y del árbol de encina (Lines 1948, Gurdián Montealegre 1996, Fig. 9 C, D). Las reproducciones de pinturas de Rafael Sanzio eran populares en el siglo XIX y en los billetes de cinco pesos de 1885 y de un peso de 1886 del Banco de la Unión se incluyen figuras de ángeles 
similares a los de la Madona Sixtina, pintada por Rafael en 1512 (Chacón Hidalgo \& Alvarado Venegas 2001). La mariquita de 1847 fue puesta en circulación según el decreto del 7 de marzo de 1847, en el cual se especificó que ...enseguidas del juramento de la Constitución se botará al Pueblo en las cabeceras departamentales por mano de los respectivos curas la cantidad de dinero que el Gobierno designe (Gurdián Montealegre 1996). Esto nos indica que la figura femenina grabada cumplía con los parámetros morales de la época, caso muy diferente al de las monedas con la india parada, censuradas posteriormente (Murillo 2004: 73) y Fig. 9C. En este contexto es oportuno citar el hecho de que Mariquita era el diminutivo con el que se conocía (Echeverría 1940) a doña María Toribia Peralta y Echeverría, esposa de don Manuel José Carazo, tendero y Ministro de Estado durante la administración (1847-1849) del Dr. Castro Madriz (Lines 1948). No sabemos si el sobrenombre mariquitas dado a las monedas de un real esté relacionado con el de doña María, o el mismo proviene de asociar la imagen en la moneda con una madona (= representación de la Virgen María), como las pintadas por Rafael Sanzio, o similar a alguna escultura en alguna iglesia, allí ...las vírgenes presentan el rostro aniñado ... y generalmente están con las manos plegadas al pecho, mirando hacia abajo (Ferrero 1981). Por ahí de 1875, en la Plaza Principal de San José (hoy Parque Central) en tiendas ambulantes se vendía, entre otras cosas, santos o cromos de carácter puramente religioso (González Zeledón 1947, Fernández Guardia 2002). Es oportuno mencionar que el busto de la mariquita mira hacia el frente, como es común en monedas conmemorativas (que no circulan). Esta moneda circuló por necesidad y la imagen se deterioró rápidamente con el uso, empezando por los rasgos faciales prominentes, como la nariz (Fig. 9A). Los griegos, contemporáneos de Calímaco, ya preferían grabar bustos mirando hacia un lado, de tal modo que el perfil del rostro sobreviviera más tiempo al desgaste de la moneda (Sutherland 1956).

\section{LOS BOLETOS DE CAFÉ}

El auge de la producción cafetalera a mediados del siglo XIX, aunado a la escasa disponibilidad de moneda acuñada, hizo necesario el empleo de boletos de café principalmente en las grandes plantaciones. Los primeros boletos conocidos en Costa Rica datan de la década de 1840 y provienen de grandes cafetales ubicados en los alrededores de la ciudad de San José. Para la segunda mitad del siglo XIX su uso se extendió a nuevas regiones agrícolas. La complejidad de los diseños de los boletos estaba, por lo general, relacionada con la capacidad económica del cafetalero (Chacón Hidalgo \& Carazo de Flores 2002). Muchos de los primeros boletos fueron acuñados en Alemania, Francia e Inglaterra. Los metales utilizados fueron cobre, aluminio, plomo y aleaciones como latón, bronce y cupro-níquel. Otros materiales utilizados fueron: bakelita, plásticos, hierro galvanizado, cuero y papel. Varias monedas nacionales y extranjeras fueron habilitadas para ser empleadas como boletos (Rojas Solano 1979?, Chacón Hidalgo \& Carazo de Flores 2002), así como fichas utilizadas en Europa en diversas actividades. En Inglaterra, entre 1649 y 1672, así como a fines del siglo XVIII y principios del XIX, la escasez de moneda acuñada de baja denominación propició el uso de moneda no oficial. En el siglo XIX los horticultores de Kent entregaban boletos (= tokens) a los cosechadores de frutas y otros productos. Estos boletos eran de metal y tenían grabadas las iniciales, o el nombre, del agricultor y de su finca, así como su valor. El valor del boleto se hacía efectivo hasta el final de la cosecha (Carson 1962). Este método, de pago temporal a trabajadores itinerantes, tal vez fue traído a Costa Rica por costarricenses que viajaron a Inglaterra a realizar estudios u otras actividades. Al igual que en Inglaterra, la escasez de moneda de baja denominación en Costa Rica, como los reales de plata, en las primeras décadas del siglo XIX, fue uno de los motivos para introducir en el país el uso de boletos en las plantaciones de café de los grandes productores (Chacón Hidalgo \& Carazo de Flores 2002, Chacón Hidalgo 2003).

Sin embargo, los boletos se continuaron utilizando mucho tiempo después de que la escasez de moneda circulante se superó. A principios del siglo XXI los boletos aún se utilizan en algunas plantaciones, para evitar el acarreo y conteo apresurado de cantidades de monedas para pagar a los cogedores, así como para disminuir la posibilidad de robo del dinero en la plantación o durante su transporte a ella. La gran mayoría de los boletos metálicos, puestos en servicio avanzado el siglo XX por los pequeños productores, son piezas 
con diseño muy sencillo. En algunos comercios, como el Almacén Gamboa, se vendían boletos a los que luego se les agregaba con un punzón la iniciales del caficultor (Fig. 10 A). Para el pequeño productor, muchos de los cuales tenían limitaciones en la disponibilidad de dinero efectivo, la razón para utilizar boletos estaba en algunos casos relacionada con la falta de dinero para el pago diario a los cogedores. Aún hoy, el caficultor debe esperar hasta el fin de semana si desea que el beneficiador le adelante una suma de dinero sobre el café que se le ha entregado y cuya cogida ya fue pagada, con dinero en efectivo o con boletos, por el caficultor. Debe recordarse que el café cosechado durante el año es pagado (deduciendo lo adelantado y el impuesto sobre la renta) hasta el próximo año y el precio final (liquidación de la cosecha) por fanega está determinado por el mercado mundial.

En algunas publicaciones recientes se utiliza el término boleto como sinónimo de ficha. Sin embargo, en el caso de Costa Rica, especialmente a mediados del siglo XX, el término boleto se le asociaba más a su uso en la industria cafetalera nacional, tanto así que el Diccionario (UTEHA 1953) los define de la siguiente forma:

Boleto: en Costa Rica, moneda de latón que en las haciendas de café se da a modo de libranza a los cogedores por cada cajuela de grano cosechado.

Ficha: pieza pequeña de cartón, metal, u otra sustancia, a la que se asigna un valor convenido y que se usa en sustitución de la moneda en algunas casas de negocios y establecimientos industriales.

En la Fig. 10 (A, B) se incluye el anverso y reverso de dos boletos típicos, de acuerdo con la definición anterior. En la Fig. 10 (C, D) se ilustra el anverso y reverso de dos fichas, de acuerdo con esa definición.

Es también oportuno mencionar que la identificación del anverso y del reverso del boleto es un poco más difícil que en el caso de las monedas, por lo que utilizamos las definiciones de Chacón Hidalgo \& Carazo de Flores (2002):

Anverso: cara principal de una moneda, boleto o medalla, en la que se encuentran el diseño, la figura y la leyenda de mayor significación.

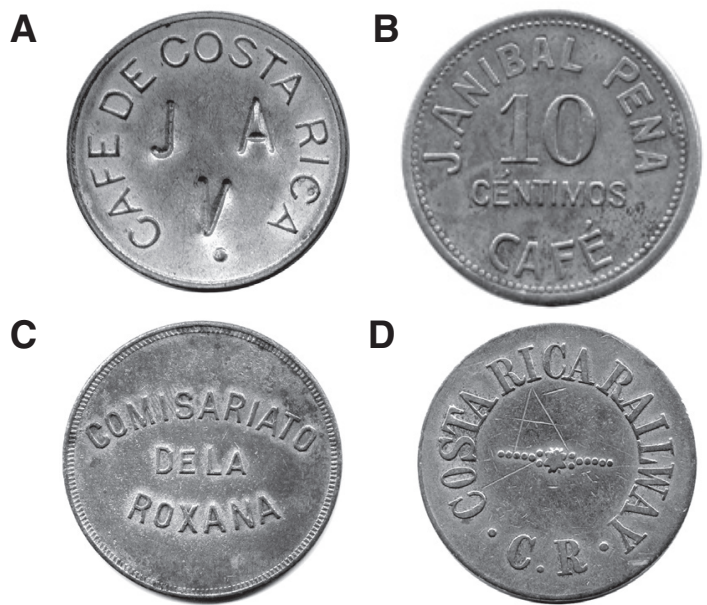

Fig. 10. Anversos de: A. Boleto de café. $24 \mathrm{~mm}$. Media cajuela. Boletos sin marcar a los que se les grababa con punzón las iniciales del nombre del caficultor (JAV en este boleto). B. Boleto de café, $20 \mathrm{~mm}, 10$ céntimos. C. Ficha del comisariato (= establecimiento comercial perteneciente a una finca o plantación) de la Roxana (Limón, Costa Rica), $39 \mathrm{~mm}$. D. Ficha del Ferrocarril de Costa Rica (Limón), 26 mm, 50 centavos. Colección privada.

Reverso: cara secundaria de una moneda, boleto o medalla. Por lo general, en él se indica el valor de la moneda y se graban figuras y leyendas complementarias.

\section{El ARbusto del CAFÉ EN LOS BOLETOS}

En el caso de las ilustraciones de plantas grabadas en los boletos de café, la situación es más compleja que con las monedas, pues la documentación sobre la emisión de boletos específicos no fue conservada, o es poco accesible por su carácter privado. Debemos entonces suponer que si la planta ilustrada se asemeja a un arbusto de café (Coffea arabica), esa era posiblemente la intención del cafetalero emisor. Las variaciones en el modelo grabado de la planta del café no harían dudar de la legitimidad del boleto, sino más bien contribuirían a diferenciarlos de los de otros cafetaleros. Hemos seleccionado algunos boletos que tienen grabadas plantas semejantes a las del cafeto (Fig. 11). Es oportuno mencionar que el arbusto de $C$. arabica tiene un solo eje central o tronco, con crecimiento vertical, que lleva opuestas dos a dos un número variable de niveles de 
A

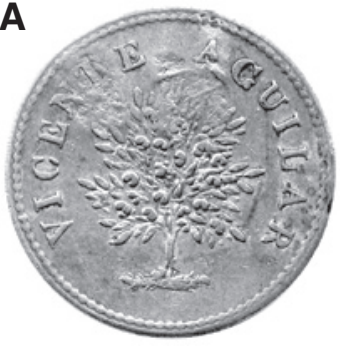

C

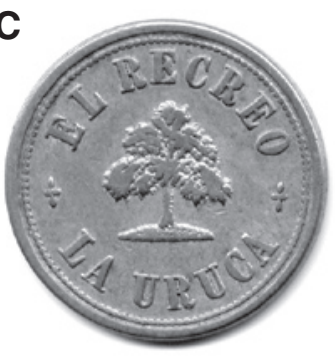

E

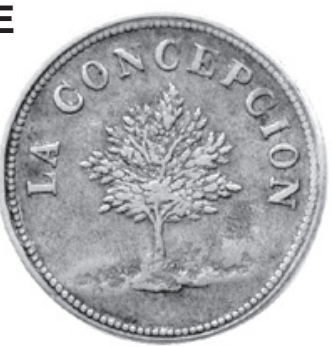

G

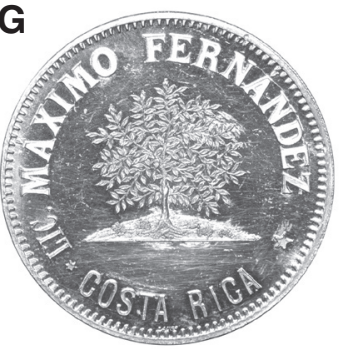

B

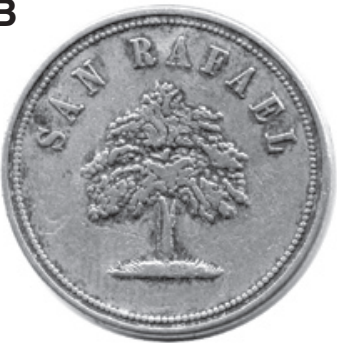

D

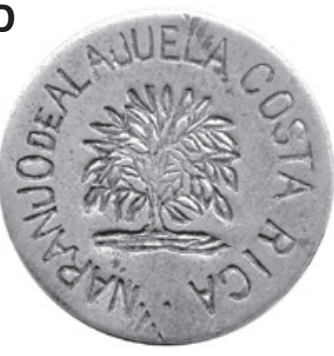

$\mathbf{F}$

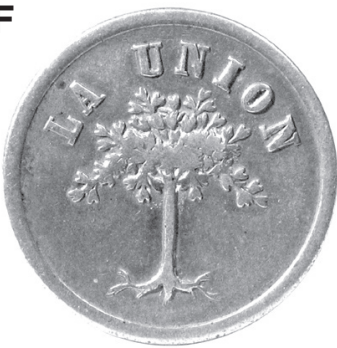

H

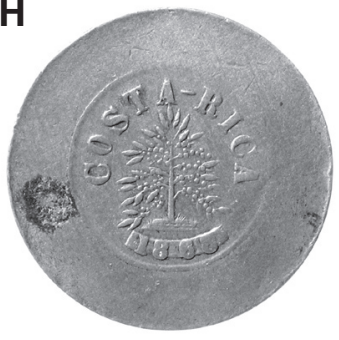

Fig. 11. Boletos metálicos, con el grabado de un arbusto semejante al cafeto (Coffea arabica) en una de sus caras: A. Vicente Aguilar. B. San Rafael. C. El Recreo-La Uruca. D. Naranjo de Alajuela, con grabado en bajorrelieve o incuso. E. La Concepción. F. La Unión. G. Máximo Fernández. H. Costa Rica-1868. Boletos A-E, colecciones privadas. Boletos F-H, colección del Museo de Numismática del Banco Central de Costa Rica. Todos los boletos reproducidos al mismo diámetro, si bien el mismo varía entre 19.5 $\mathrm{mm}$ (E) y $24 \mathrm{~mm}$ (D).

ramas primarias (bandolas) que crecen perpendiculares al eje, tal como se ilustra en la Fig. $11 \mathrm{H}$. Al crecer estas ramas y el tronco dan al arbusto una forma cónica, como en la Fig. 11 (B, C). El cafeto con poda produce

formas similares a las ilustradas en la Fig. 11 (D, G). $\mathrm{El}$ arbusto sin podar lleva a un alargamiento del tronco, la disminución del número de ramas primarias bajas y el desarrollo de una copa (Coste 1968), semejante al ilustrado en la Fig.11 (F). Como dato curioso anotamos que los cafetos más antiguos del país están en la Isla del Coco y aún producen grano. Estos arbustos tienen su origen en los plantados a fines del siglo XIX (Pittier 1889), para proveer de café a los residentes. No sabemos si se utilizaron boletos en esa plantación.

\section{OTRAS PLANTAS GRABADAS EN LOS BOLETOS DE CAFÉ}

El hecho de que ilustraciones de otras especies de plantas (Fig. 12) están grabadas en algunos boletos o en fichas utilizados por caficultores de Costa Rica, puede deberse a que fueron emitidos para su uso en otro tipo de cosecha, en transporte, o en juegos de azar y luego adaptados en Costa Rica para su empleo como boletos de café. Algunos de éstos boletos tal vez fueron importados de Europa y tienen grabadas plantas asociadas a ritos y tradiciones, como la encina (Quercus sp., Fig. 12 B, C) y el trébol (Trifolium sp., Fig. $12 \mathrm{~J}, \mathrm{~K}$ ). El balance entre realidad (representación fiel de la planta) y subjetividad (representación artística de la planta) hace que algunas especies sean difíciles de separar, como ocurre con el mirto (Myrtus communis, Myrtaceae) y el laurel (Laurus nobilis, Lauraceae), cuando sus hojas y frutillos son grabados a escala similar (Fig. 12 E, H, I). Algunos cafetaleros a fines del siglo XIX tomaron las monedas de un centavo (emitidas entre 1865 y 1874), así como las de dos céntimos de 1903 que se habían devaluado y eran poco útiles en las operaciones comerciales, y las convirtieron en boletos mediante una letra, las iniciales del nombre, y en otros casos haciendo desaparecer todo el grabado original de la moneda para establecer un boleto a su gusto. Esto ocurrió en gran parte con los centavos de 1865 , por lo que las monedas originales sin contramarcar son difíciles de obtener por los coleccionistas (Rojas Solano 1979?). En la Fig. $12(\mathrm{H})$ se incluye una de estas monedas de un centavo habilitada como boleto de café al marcarla con las letras L O W y LM en el círculo sobre el escudo. También se habilitaron como boletos varias monedas extranjeras (ver Rulau 2000). La fabricación 
A

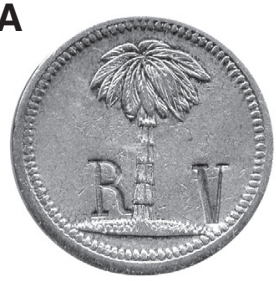

E
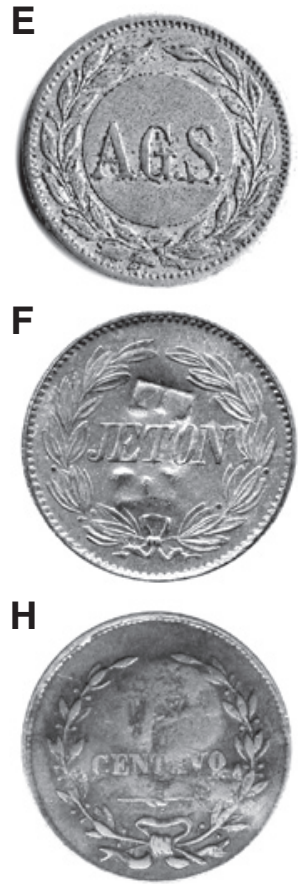

B
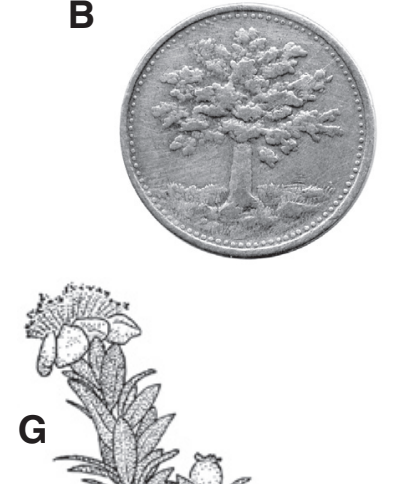

I
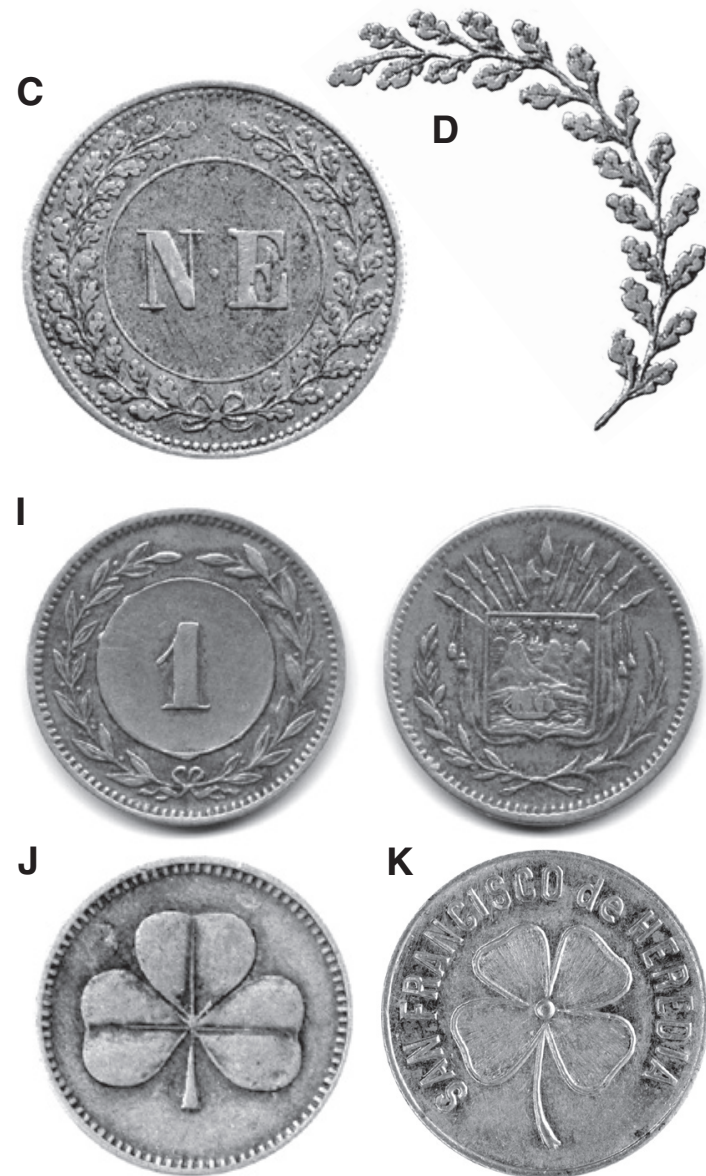

Fig. 12. Boletos con ilustraciones de otras especies de plantas: A. Palmera semejante, por los nudos del tronco, al cocotero (Cocos nucifera, Arecaceae), $20 \mathrm{~mm}$. B. Un árbol semejante a la encina (Quercus sp., Fagaceae), $21 \mathrm{~mm}$. C. Boleto con iniciales NE entre dos ramas con hojas de encina, $24 \mathrm{~mm}$. D. Detalle de la rama de la encina. E. Boleto con iniciales AGS entre dos ramas con hojas y frutillos pedunculados semejantes al laurel (Laurus nobilis, Lauraceae), 19.5 mm. F. Boleto con dos ramas similares al mirto europeo (Myrtus communis, Myrtaceae), $19 \mathrm{~mm}$. G. Detalle de una rama de M. communis basado en un ejemplar vivo cultivado en Santo Domingo de Heredia, Costa Rica. H. Anverso y reverso de la moneda de un centavo, 1865, $20 \mathrm{~mm}$, habilitada como boleto de café. I. Anverso y reverso del boleto, fabricado posiblemente por la Casa de Moneda, San José. El número 1 está rodeado por dos ramas semejantes al laurel, así como el escudo nacional tiene en su base una palma (?) y una rama de mirto. J. Boleto con una hoja de trébol (Trifolium dubium, Fabaceae), 19 mm. K. Boleto con hoja de trébol con cuatro hojas, forma de T. dubium, símbolo de buena suerte. Solamente el boleto E tiene en su anverso la fecha de emisión (1914). Boletos A-J, colecciones privadas. Boleto K, Museo de Numismática, BCCR.

de boletos y punzones se hacía a veces en forma privada en Costa Rica por los mismos grabadores de la Casa de Moneda de San José, como lo relata en sus escritos el grabador Cruz Blanco entre 1863 y 1868 (Murillo 2004). En la Fig. 12 (I) se incluye un ejemplo de boleto que, por tener grabado el escudo nacional de Costa Rica, tal vez fueron fabricados en la Casa de Moneda de San José. Es oportuno mencionar que en algunas pruebas de monedas de un centavo hechas entre 1890 y 1892 por la Casa de Moneda, contienen el escudo nacional con las dos ramas (palma y mirto) que se cruzan hacia el borde de la moneda (Robinson 1965), al igual que en el boleto ilustrado en la Fig. 12 (I).

En la Fig. $12 \mathrm{~F}$ se incluye un boleto con la leyenda $J E T O N$, palabra que tiene un significado similar al de 

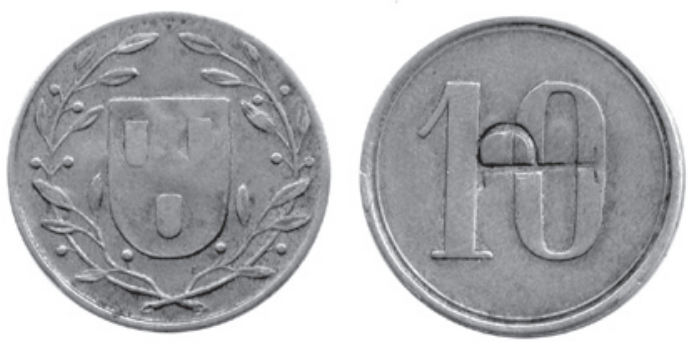

Fig. 13. Boleto de café utilizado en Costa Rica. $20 \mathrm{~mm}$. Dos ramas de olivo (Olea europaea) con frutos (aceitunas) inmaduras y contramarca $\mathrm{P}$, sobre el número 10. Colección privada.

ficha en otros idiomas. Los jeton tuvieron su origen en Francia en el siglo XIII como piezas metálicas para llevar las cuentas sobre un tablero cuadriculado y siglos después, en juegos de cartas (Carson 1962). El boleto de café ilustrado en la Fig.13 incluye dos ramas que podrían ser de olivo (Olea europaea, Oleaceae), pues son nudosas, angulares y llevan hojas con pecíolo corto, opuestas, oblongas, o aovadas. Los frutos son similares a los del olivo (aceitunas inmaduras). En Grecia, el olivo era un árbol consagrado a Minerva, protectora de Atenas, y aparece en monedas de esa ciudad por ahí del año 450 A.C. (Sutherland 1956). Con sus ramas se hacían coronas para los ciudadanos ilustres, así como para los vencedores en los juegos olímpicos. El olivo es símbolo de paz y de prosperidad (UTEHA 1953). La pieza ilustrada está contramarcada con la letra P y tal vez fue utilizada como boleto de café con un valor de 10 céntimos, o de 10 colones, o de 10 medidas (= cajuelas). En monedas italianas recientes se representa a Minerva de pie, sosteniendo la rama de un árbol joven de laurel, en vez de olivo (Numismatica e Monete Italiane, http//incuso.altervista.org).

La publicación reciente de varios libros, como los de Dueñas Leiva (1994), Gurdián Montealegre (1997), Carranza Astúa (2001), Chacón Hidalgo \& Carazo de Flores (2002), Chacón Hidalgo (2003) y Murillo (2004), ha producido un auge en el estudio de la numismática costarricense. Este auge posiblemente lleve a la búsqueda de más información sobre las plantas grabadas en monedas, billetes, medallas y boletos de Costa Rica.

Agradecimientos. A Jenaro Acuña por la revisión del manuscrito. A Minor Martin y Rodolfo Fernández, por sus comentarios. A Harlan K. Dean, Karla Johanning y Roberto Chaverri, por ayuda bibliográfica. A varios coleccionistas que nos facilitaron boletos y al Museo de Numismática por algunas de las imágenes utilizadas en las Figs. 11 y 12. A la Prof. Adriana Zamora por el ejemplar de mirto cultivado. A Jeffrey Sibaja por dibujar las ilustraciones a tinta y a Sergio Aguilar por diagramar el texto y ensamblar las figuras. Este trabajo está dedicado a la memoria del Prof. José Antonio Vargas Salas (1916-2003), Maestro Normal (19381968), agricultor y artesano.

\section{LiTERATURA CITADA}

Acuña Ortega V.H. 1986. Patrones del conflicto social en la economía cafetalera costarricense (1900-1948). Ciencias Sociales 31: 113-122.

Alfaro, A. 2003. La cotidianidad de un canastero. Herencia 15(2): 91-103.

Bariatti, R. 2000. La inmigración italiana en Costa Rica (Sexta parte): El aporte italiano al Teatro Nacional. Revista Académica (U.A.C.A) 26: 229-234.

Bartolini, D. (Director). 1949. Acanto. In: Enciclopedia Italiana. Tomo I. Instituto Poligrafico dello Statto. Roma. p. 174-177.

Berry, F. \& W.J. Kress. 1991. Heliconia. An Identification Guide. Smithsonian Institution Press. Washington. $334 \mathrm{p}$.

Burger, W. 1977. Flora Costaricensis: Fagaceae. Fieldiana, Bot. 40: 59-82.

Carranza Astúa, J.A. 2001. Historia de los billetes de Costa Rica 1858-2001. Fundación Museos del Banco Central - Litografia e Imprenta LIL. San José. 231 p.

Carson, R.A.G. 1962. Coins of the World. Harper \& Brothers. New York. 706 p.

Chavarría, L. 2003. Manojo de Guarias. Editorial UNED. San José. $52 \mathrm{p}$.

Chacón Hidalgo M.B. \& I. Alvarado Venegas. 2001. Gráfica en el papel moneda (1858-1936). Fundación Museos del Banco Central, San José. 68 p.

Chacón Hidalgo, M.B. \& E. Carazo de Flores. 2002. Los boletos de café en Costa Rica. Folleto Técnico. Fundación Museos del Banco Central. San José. 20 p.

Chacón Hidalgo, M.B. 2003. Monedas de Costa Rica. Reseña Histórica. Editorial de la Universidad de Costa Rica. San José. 87 p.

Cruells, E. 2000. Historia del Arte. Vol. 16. Alto Renacimiento I. Salvat Editores, S.A. Barcelona. 96 p.

Dressler, R.L. \& W.E. Higgins. 2003. Guarianthe, generic name for the "Cattleya" skinneri complex. Lankesteriana 7: 37-38.

Dueñas Leiva, T. 1994. Monedas tipo de Costa Rica. Editorial UNED, San José. 71 p.

Echeverría, M. 1940. Cosas de antaño. Educación 82-83: 21-32. 
Espasa, J. (Editor). 1924. Acanto. In: Enciclopedia Universal Ilustrada Europeo-Americana. Tomo I. Espasa-Galpe, S.A. Madrid. p. 902-906.

Fernández Guardia, R. 2002. Costa Rica en el Siglo XIX: Antología de Viajeros. Editorial UNED. San José. 495 p.

Ferrero, L. 1981. Sociedad y Arte en la Costa Rica del siglo XIX. Editorial UNED. San José. 214 p.

Fournier, L.A. \& E.G. García. 1998. Nombres vernaculares y científicos de los árboles de Costa Rica. Editorial Guayacán. San José. 262 p.

González Zeledón, M. 1947. Cuentos de Magón. Editorial Universitaria, San José. 403 p.

Green, P. 2003. Rumors of great rarities make the round. World Coin News 30 (12): 58-60.

.2004a. Central Americans serious about coin buys. World Coin News 31 (6): 64-66.

.2004 b. Costa Rican rarities not often auctioned. World Coin News 31 (12): 68-70.

Gudmundson, L. 1990. Campesino, granjero, proletario: formación de clase en una economía cafetalera de pequeños propietarios 1850-1950. Revista de Historia 21-22: 151-206.

Gurdián Montealegre, R. 1996. Contribución al estudio de las monedas de Costa Rica. $2^{\text {da }}$ ed. Litografía e Imprenta LIL. San José. 186 p.

Hammel, B.E., M.H. Grayum, C. Herrera \& N. Zamora (Eds). 2003. Manual de Plantas de Costa Rica. Vol. II. Gimnospermas y Monocotiledóneas (Agavaceae-Musaceae). Missouri Bot. Gard. Press. St. Louis. 694 p.

Instituto del Café de Costa Rica (ICAFE). 1989. Manual de recomendaciones para el cultivo del café. $6^{\text {ta }}$ Ed. Programa Cooperativo ICAFE-MAG. Litografía e Imprenta LIL. San José. 122 p.

Keen, M. 1971. Sea shells of Tropical West America. Stanford University Press, Stanford. $1160 \mathrm{p}$.

León, J. 1987. Botánica de los cultivos tropicales. Instituto Interamericano de Ciencias Agrícolas (IICA). IICA, San José. 445 p.

Lines, J.A. 1948. Las monedas de oro y plata emitidas por el Doctor Castro. Revista de los Archivos Nacionales 9/10: 505-513.

Meléndez, C. 2000. Historia de Costa Rica. Editorial UNED. 175 p.

Molina I. 1987. Habilitadores y habilitados en el Valle Central de Costa Rica: el financiamiento de la producción cafetalera en los inicios de su expansión (18381850). Revista de Historia 16: 85-128

Murillo, J. 2004. Historia de las monedas de Costa Rica. Catálogo Numismático. Editorial UNED, San José. $252 \mathrm{p}$.

Obregón Quesada, C. 1996. El Teatro Nacional. Imprenta Ciudad Hogar Calasanz. San José. 24 p.

Picado, C. 1913. Les Bromeliacées épiphytes considérées comme milieu biologique. Theses. Faculté des Sciences de Paris. Imprimerie L. Daniel. Paris. 164 p.
Pittier, H. 1899. Apuntamientos preliminares sobre la Isla de Cocos, posesión costarricense en el Océano Pacífico. Memoria de la Secretaria de Fomento (Costa Rica) 1899: 15-28.

Palma, T. \& A. Chaves. 2000. Algunas lianas del trópico húmedo empleadas en artesanía. Colección Productos no Maderables del Bosque. Serie Técnica No. 1. Instituto Tecnológico de Costa Rica-Fundecooperación. San Carlos. 55 p.

Robinson, C.M. 1965. The coins of Central America 17331965. Charles Robinson. San Benito. 131 p.

Rojas Solano, H. 1979 (?). Los boletos y su función social y económica. Oficina del Café de Costa Rica. Artes Gráficas de Centro América. San José. 48 p.

Rulau, R. 2000. Latin American Tokens. $2^{\text {nd }}$ ed. Krause Publications, Iola. 479 p.

Soto, M. 1985. Bananos: cultivo y comercialización. Litografía e Imprenta Lil. San José. 648 p.

Solano Pérez, W. 1995. El día de trabajo en la Hacienda Aragón, Turrialba, 1943. Revista de Historia: 133-174.

Sutherland, C.H.V. 1956. Art in Coinage. The aesthetics of money from Greece to the present day. Philosophical Library. New York. 223 p.

Stiles, F.G. \& A.F. Skutch. 1989. Birds of Costa Rica. Cornell University Press, Ithaca. 511 p.

Ulloa Zamora, A. 1970. El Teatro Nacional. Tesis de Licenciatura en Filosofía y Letras. Universidad de Costa Rica, San Pedro. 143 p.

Unión Tipográfica Editorial Hispano Americana (UTEHA). 1953. Diccionario Enciclopédico. Tomos I-XII. Impresora y Litográfica Azteca, México.

Vega Jiménez, P. 2004. Con sabor a tertulia: historia del consumo de café en Costa Rica (1840-1940). Oficina del Café - Editorial de la Universidad de Costa Rica. San José. 265 p.

Valerio, R. 1944. Los nombres vulgares de la fauna costarricense. Universidad de Costa Rica. Facultad de Ciencias. San José. 85 p.

Vargas-Zamora, J.A. \& J. Gómez-Laurito. 2004. Botánica y Numismática: Las plantas en las monedas de Costa Rica (1709-2004). Lankesteriana 4(2): 155-168.

Vargas-Zamora, J.A. 2005. La Numismática en los Cuentos de Magón. Apuntes para la conferencia impartida en el Auditorio de los Museos del BCCR, en el 180 Aniversario de la Primera Moneda Acuñada en Costa Rica, San José, 19 febrero 2005. 20 p.

Villalobos Rodríguez, J., H.L. Chacón de Umaña \& J.F. Sáenz Carbonell. 2000. Braulio Carrillo. El Estadista. Tomo II. Imprenta Nacional. San José. 619 p.

Zamora, N.S. \& T. Pennington. 2001. Guabas y cuajiniquiles de Costa Rica (Inga spp.). Edit. INBIO, Santo Domingo de Heredia. 200 p.

Zeledón Cartín, E. 2004. Del viejo San José. Colección Crónicas Cotidianas Costarricenses. Editorial UCR. San José. 187 p. 